EESTI NSV TEADUSTE AKADEEMIA TOIMETISED. XV KÖIDE

FUUSIKA-MATEMAATIKA- JA TEHNIKATEADUSTE SEERIA. 1966, NR. 3

ИЗВЕСТИЯ АКАДЕМИИ НАУК ЭСТОНСКОИ ССР. ТОМ ХV СЕРИЯ ФИЗИКО-МАТЕМАТИЧЕСКИХ И ТЕХНИЧЕСКИХ НАУК. 1966, № 3

\title{
ПРЯМОЕ ОПРЕДЕЛЕНИЕ ОТНОШЕНИЯ УГЛЕРОДА И КИСЛОРОДА В ГАЗОХРОМАТОГРАФИЧЕСКИХ ЭЛЮЕНТАХ
}

В последнее время для ускорения элементарного а́нализа все более широкое распространение получают приемы газохроматографического анализа: продукты сжнгания анализируемого вещества разделяют в газохроматографической колонке и детектируют соответствуюшим способом. Налажено серийное производство газохроматографических приборов разной конструкции для определения углерода и водорода [1].

Значительно ускоряет элементарный анализ также исключение предварительного взвешивания вецества: по продуктам сжигания определяют отношение $\mathrm{C} / \mathrm{H}$, что часто и является целевым результатом анализа.

Так как газохроматографическое разделение доходит до индивидуальных соединений, установление элементарного состава исходной, в большинстве случаев сложной, многокомпонентной смеси мало помогает идентификации ее компонентов. Сущестьенно важнее узнать состав каждого компонента. Поэтому сделаны попытки сжигать газохроматографическн разделєнные компоненты в реакторе за газохроматографической колонкой, а количество продуктов сжигания каждого компонента определять при помощи второй газохроматографической установки [2] или дифференциальным поглощением углекислого газа и воды [3,4].

Реакционнохроматографические методы нспользозались также для определения азота [5] и серы [6] в органических соединениях. Для определения кислорода аналогичные методы не разработаны.

В Институте химии АН ЭССР уже несколько лет с помощью преимущественно хроматографических методов изучают сланцевую смолу, содержащую $50 \%$ кислородных соединений.

При выполнении этих работ возникла необходимость в методе определения кислорода в газохроматографически разделенных компонентах. Косвенные методы анализа (остаток после вычета углерода и водорода) в условиях газохроматографического анализа не приемлемы. В связи с этим был разработан соответствующий метод, описанию которого и посвящена настоящая статья. В работе использован опыт прямого микроаналитического определения кислорода [?].

Один из старейших способов (метод Тер Мейлена) основывается на каталитической гидрогенизации соединений, при этом из кислорода образуется вода. Последняя определяется каким-нибудь из известчых способов.

В последнее время проводят пиролиз органических соединений на активированном угле, нагретом до $1100^{\circ} \mathrm{C}$, в токе инертного газа. При этом кислород количественно переходит в СО, который обычно определяется йодометрически.

В настоящей работе был использован опыт обоих методов, отдельно и комбинированно. 


\section{Гидрокрекинг кислородных соединений на никелевом катализаторе}

В ходе одной из прежних работ [8], посвященной изучению гидрирующих-дегидрирующих катализаторов, выяснилось, что при температурах, превышающих $200^{\circ}$, органические соединения на никелевом катализаторе сильно разлагаются. Крекирующие свойства никеля известны также по данным литературы $\left[{ }^{9},{ }^{10}\right]$, и они использованы в газохроматографическом анализе. Установлено, что на указанном катализаторе, в токе водорода при $450^{\circ}$, органические соединения полностью разлагаются до метана. При проведении реакции за хроматографической колонкой объем реакционных продуктов значительно превышает объем исходных элюатов, вследствие чего чувствительность детектора повышается. Воду, образующуюся при анализе кислородных соединений, обычно поглощают до детектора.

В настоящей работе отношение атомов C/O определялось двухкратным проведением крекинга газохроматографически разделенных компонентов. Сперва через детектор пропускались все реакционные продукты $\left(\mathrm{CH}_{4}+\mathrm{H}_{2} \mathrm{O}\right)$, при втором пропускании воду удаляли до детектора. Чем сильнее уменьшаются пики после адсорбции воды, тем большему содержанию кислорода они соответствуют.

Более точные данные дает математический анализ результатов. Қак показали дальнейшие опыты с эталонами, практические результаты хорошо совпадают с литературными данными [11], по которым молекулярная чувствительность катарометра по метану равна 36 , по воде - 21 (бензол принят за 100).

Для изготовления никелевого катализатора азотнокислый никель растворяли в малом количестве воды и прибавляли соответствующее количество носителя (диатомит, пористое стекло). Воду испаряли при перемешивании в вакууме водоструйного насоса. Қатализатор восстанавливали в реакторе, одновременно повышая его температуру до рабочей. Реакторы изготовлялись из меди, коррозионностойкой стали и кварца. Под конец применялись только кварцевые трубки.

В работе использовали двухколоночный хроматограф УХ-1. Реактор был поставлен в трубчатую печь длиной 20 см.

В начале работы определяли оптимальную температуру гидрокрекинга, при которой не остается исходного вещества и не образуется других продуктов кроме метана. Для этого устанавливали реактор, содержащий 250 мг $\mathrm{Ni}$ на 2 мл диатомита, до аналитической колонки. В качестве исследуемых веществ применялись: циклогексанон, дибутиловый эфир, $м$-крезол, н-гексилащетат, н-гептанол, этиловый эфир изомасляной кислоты и другие.

Для анализа продуктов катализа использовали три колонки: 6-метровую апиезоновую колонку для установления полноты распада исходного вещества, 6-метровую дибутилфталатную - для анализа образовавшихся углеводородов и 3-метровую силикагелевую - для анализа газов.

Выяснилось, что при $250-300^{\circ}$ исходного вещества не остается, а выше $400^{\circ}$ образуется только метан. Но при этом соединения задерживаются на катализаторе, особенно при низких температурах, вследствие чего симметричность пиков ухудшается. Исследованйя показали, что адсорбцию обусловливают как металл, так и носитель. При проверке разных носителей и концентраций металла оказалось, что самую низкую адсорбционную способность имеет пористое стекло, содержащее 7 - 12 мг $\mathrm{Ni}$ в 1 мл. При дальнеӥшем использовании в реакторе $2-3$ мл такого 
катализатора гидрокрекинг проходил на нем полностью до метана, несмотря на низкое содержание металла.

Пористое стекло $(0,3-1,0$ мм) получали из измельченного $(<0,1$ мм $)$ стекла путем спекания при $500-600^{\circ}$ и последующего дробления [12].

Путем гидрокрекинга смеси разных соединений в пределе температур $250-400^{\circ}$ было установлено, что по стабильности их можно расположить в следующий ряд: спирты < кетоны < сложные эфиры < простые эфиры $<$ углеводороды.

Гидрирующая-дегидрирующая способность никелевого катализатора оказалась низкой.

При элементарном анализе газохроматографическим способом важное место занимает количественная интерпретация хроматограмм. Измерение ширины пиков вызывает относительно большую ошибку при вычислении их площадей. В работе [3] для повышения точности ширину пиков измеряли с точностью до 0,01 мм.

В настоящей работе результаты (отношение атомов C/O) получали путем сравнения двух хроматограмм, отличающихся только высотой пиков. Учитывалось то обстоятельство, что при одинаковых условиях анализа ширина пика при изменении количества соответствующего компонента остается стабильной, изменяется только высота пика [13-15]. При количественном расчете сравнивали высоты пиков на каждой хроматограмме с высотой пика одного компонента (ключевого), отношение С/O которого известно. Еще лучше при расчете продуктов гидрокрекинга принимать за ключевой компонент углеводород, из которого воды не образуется.

В дальнейшей работе для газохроматографического разделения использовали колонку длиной 6 м и диаметром 6/4 мм. Неподвижной фазой служил полиэтиленгликоль 4000 в количестве $20 \%$ от носителя хромосорба W. Расход водорода составлял $60 \mathrm{~m} / \mathrm{Muн}$, хроматографирование велось при 100 или $150^{\circ}$.

Для проведения элементарного анализа реактор включали за аналитической колонкой - вместо второй колонки аппарата УХ-1. При определении содержания $\mathrm{CH}_{4}+\mathrm{H}_{2} \mathrm{O}$ газ направляли из реактора прямо в детектор, а при определении одного $\mathrm{CH}_{4}$ газ предварительно пропускали через колонку (длина $20 \mathrm{~cm}$, диаметр 5 мм) с силикагелем, которая задержала пары воды.

При теоретическом расчете отношений высот пиков, содержащих соответственно $\mathrm{CH}_{4}+\mathrm{H}_{2} \mathrm{O}$ и $\mathrm{CH}_{4}$, в зависимости от отношения $\mathrm{C} / \mathrm{O}$ в молекулах были получены данные, представленные в табл. 1. Расчеты проведены на основе литературных данных о молекулярных теплопроводностях метана и воды [11].

Таблица 1

Зависимость количества продуктов гидрокрекинга от атомарного отношения С/0 в молекулах

\begin{tabular}{c|c|c|c|c|c|c|c|c}
\hline $\mathrm{C} / \mathrm{O}$ & 1 & 2 & 3 & 4 & 5 & 6 & 7 & 8 \\
\hline $\mathrm{CH}_{4}+\mathrm{H}_{2} \mathrm{O}$ & 1,582 & 1,290 & 1,195 & 1,147 & 1,118 & 1,097 & 1,082 & 1,073 \\
\hline $\mathrm{CH}_{4}$ & & & & & & &
\end{tabular}

Чтобы установить, в какой мере практические результаты совпадают с теоретическим расчетом, был проведен гидрокрекинг разных искусст- 
Таблица 2

Oпределение содержания кислорода различных соединений путем гидрокрекинга на никелевом катализаторе

\begin{tabular}{|c|c|c|c|c|c|c|}
\hline & \multicolumn{2}{|c|}{$\mathrm{CH}_{4}+\mathrm{H}_{2} \mathrm{O}$} & \multicolumn{2}{|c|}{$\mathrm{CH}_{4}$} & $\frac{\mathrm{CH}_{4}+\mathrm{H}_{2} \mathrm{O}}{\mathrm{CH}_{4}}$ & $\mathrm{C} / \mathrm{O}$ \\
\hline $\begin{array}{l}\text { Температура реактора, }{ }^{\circ} \mathrm{C} \\
\text { Высота пика толуола, мм } \\
\text { Относительные высоты пи- } \\
\text { ков: } \\
\text { циклогексана } \\
\text { этилацетата } \\
\text { бутанона-2 } \\
\text { дибутилового эфира } \\
\text { пропанола-1 } \\
\text { толуола }\end{array}$ & $\begin{array}{l}0,346 \\
0,510 \\
0,536 \\
0,730 \\
0,657 \\
1,000\end{array}$ & $\begin{array}{l}0,352 \\
0,510 \\
0,538 \\
0,755 \\
0,680 \\
1,000\end{array}$ & $\begin{array}{l}0,336 \\
0,408 \\
0,472 \\
0,699 \\
0,563 \\
1,000\end{array}$ & $\begin{array}{l}0,340 \\
0,407 \\
0,468 \\
0,698 \\
0,550 \\
1,000\end{array}$ & $\begin{array}{r}1,032 \\
1,252 \\
1,142 \\
1,061 \\
1,198 \\
1,000\end{array}$ & $\begin{array}{l}-\overline{2} \\
4 \\
8 \\
3 \\
-\end{array}$ \\
\hline
\end{tabular}

венных смесей кислородных соединений. В первых опытах в соединениях было получено значительно меньше кислорода, чем ожидали. Выяснилось, что небольшие количества воды, образующиеся при гидрокрекинге, задерживаются где-то в аппаратуре. При введении малых количеств воды (до 1 мкл) ее пика также не получили. Поскольку место сорбции воды обнаружить не удалось, было решено насыщать эти неизвестные активные точки постоянным прибавлением к газу-носителю малых количеств воды. Для этого в патрубок, предусмотренный для осушки газа, помещали 30 мл силикагеля, пропитанного $3-4$ мл воды. Дальнейшие опыты показали, что небольшие количества воды в аппаратуре больше не пропадают, значительно улучшилась также симметричность пика воды $\left[{ }^{16}\right]$, в то время как ухудшения селективности разделения вследствие влажного газа, отмеченного в литературе [17], не наблюдалось.

Результаты анализа одной смеси разных кислородных соединений представлены в табл. 2, а второй смеси, все компоненты которой имеют $\mathrm{C} / \mathrm{O}=4$, в табл. 3. На основании средних результатов нескольких опытов были рассчитаны отношения $\mathrm{CH}_{4}+\mathrm{H}_{2} \mathrm{O} / \mathrm{CH}_{4}$, которые также приводятся в названных таблицах. Хроматограммы второй смеси приведены на рис. 1 .

Таблица 3

Определение содержания кислорода соединений, имеющих $\mathrm{C} / \mathrm{O}=4$, гидрокрекингом на никелевом катализаторе

\begin{tabular}{|c|c|c|c|c|c|c|c|c|}
\hline & \multicolumn{3}{|c|}{$\mathrm{CH}_{4}+\mathrm{H}_{2} \mathrm{O}$} & \multicolumn{3}{|c|}{$\mathrm{CH}_{4}$} & $\frac{\mathrm{CH}_{4}+\mathrm{H}_{2} \mathrm{O}}{\mathrm{CH}_{4}}$ & № пи- \\
\hline $\begin{array}{l}\text { Температура реакто- } \\
\text { ра, }{ }^{\circ} \mathrm{C} \\
\text { Высота пика этилбен- } \\
\text { зола, мм } \\
\text { Относительные высо- } \\
\text { ты пиков: } \\
\text { бутанона-2 } \\
\text { изобутанола } \\
\text { n-бутанола } \\
\text { этилбензола }\end{array}$ & $\begin{array}{r}470 \\
117,5 \\
0,728 \\
0,558 \\
0,902 \\
1,000\end{array}$ & $\begin{array}{r}465 \\
238 \\
\\
0,744 \\
0,568 \\
0,886 \\
1,000\end{array}$ & $\begin{array}{r}460 \\
182 \\
\\
0,742 \\
0,566 \\
0,893 \\
1,000\end{array}$ & \begin{tabular}{|l}
\multicolumn{1}{l}{$\begin{array}{l}2185 \\
\end{array}$} \\
\\
0,658 \\
0,468 \\
0,773 \\
1,000
\end{tabular} & 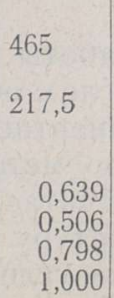 & $\begin{array}{l}0,648 \\
0,489 \\
0,790 \\
1,000\end{array}$ & $\begin{array}{l}1,139 \\
1,156 \\
1,135 \\
1,000\end{array}$ & $\begin{array}{l}1 \\
2 \\
3 \\
4\end{array}$ \\
\hline
\end{tabular}




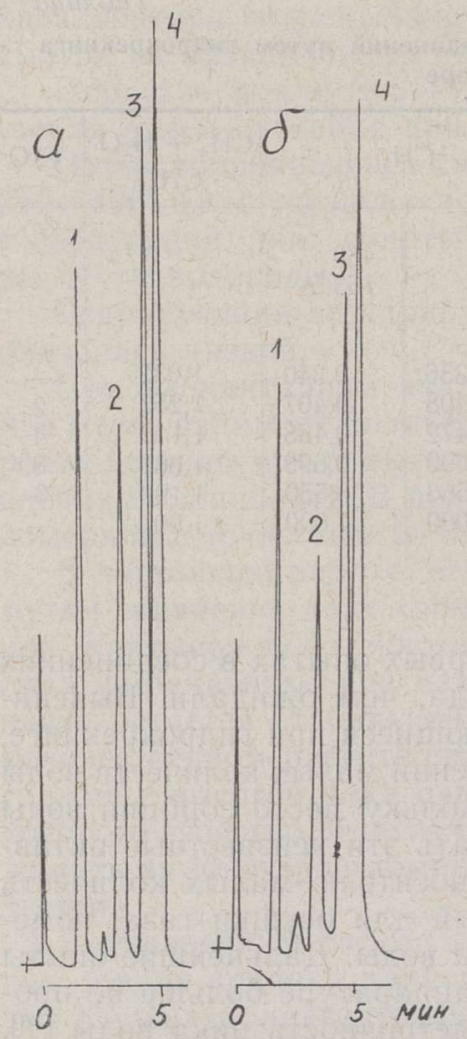

Несмотря на то, что ошибка измерения высот пиков искусственных смесей достигает $+1,5$ мм, большинство относительных высот пиков параллельных опытов имеют близкие значения. Это указывает на то, что удельное значение других ошибок (четкостьхроматографического разделения, полнота гидрокрекинга и адсорбции на силикагеле, стабильность детектора) еще меньше. Суммарная абсолютная ошибка при изменении $\mathrm{CH}_{4}+\mathrm{H}_{2} \mathrm{O} / \mathrm{CH}_{4}$ лежит в пределах $\pm 0,015$ единиц. Отсюда следует, что названным методом можно пользоваться только в низкомолекулярной области. Если $\mathrm{C} / \mathrm{O}>5$, то точных данных о количестве углеродных атомов в молєкулах получить невозможно, так как различия относительных высот пиков: лежат уже в пределах ошибки (см. табл. 1).

Рис. 1. Хроматограммы кислородных соединений $\mathrm{C}_{4}$. После разделения в колонке проведен гидрокрекинг на никелевом катализаторе: $a-$ элюаты содержат метан и воду; б-вода адсорбирована на силикагеле, элюаты содержат только метан. Названия компонентов см. в табл. 3.

Применение метода ограничивается низкой чувствительностью катарометра по водяному пару. Попытки превращения воды с помощью реактива Гриньяра в углеводороды, хорошо детектируемые катарометром, не дали желаемых результатов.

Превращение воды с помощью карбида кальция в ацетилен (наиболее часто используемое в газохроматографической практике), ужє стехиометрически мало выгодно. Отсюда следует, что самостоятельное использование метода гидрокрекинга ограничено.

Как известно, никелевые катализаторы чувствительны к различным ядам. Хотя с большинством соединений катализаторы работали продолжительное время, некоторые соединения (циклокетоны, ароматические соединения в больших количествах) понижали крекирующую активность. Катализатор удалось регенерировать 1 -2 раза путем продувания воздухом, после чего его заменяли.

\section{Пиролиз кислородных соединений на угле}

В этом разделе работы газохроматографически разделенные компоненты разлагали на угле с образованием СО из кислорода. Обычно пиролиз проводят в токе инертного газа.

Унтерцаухер, автор метода, считает необходимой температурой пиролиза $1120^{\circ}$, Шюце считает достаточной $1000^{\circ}[7]$. В присутствии катализаторов эту температуру можно снизить. Так, щелочи понижают температуру до $800^{\circ}$, а на угле, содержащем $50 \%$ платины, пиролиз протекает уже при $900^{\circ}\left[{ }^{18}\right]$. 
В работе [19] были использованы газохроматографические приемы. Анализируемое вещество $(2 \div 30$ мг) пропускали в токе водорода через трубку (длина 400 мм, диаметр 10 мм) с углем, нагретым до $1120^{\circ}$. Продукты пиролиза $\left(\mathrm{CO}, \mathrm{N}_{2}\right)$ разделяли на угольной колонке при комнатной температуре.

При пиролизе проходят следующие равновесные реакции восстановления $\left[{ }^{20}\right]$ :

$$
\begin{aligned}
& \mathrm{C}+\mathrm{CO}_{2}=2 \mathrm{CO} \quad-38400 \kappa \kappa a \Omega / \kappa м о \Omega ь \\
& \mathrm{C}+\mathrm{H}_{2} \mathrm{O}=\mathrm{CO}+\mathrm{H}_{2}-31640 \kappa \kappa a \Omega / \kappa м о л ь
\end{aligned}
$$

Желательной реакции способствует повышение температуры, а также низкое давление, которое и имеет место в реакторе.

Для нагрева реактора применялась печь для микроэлементарного анализа длиной 20 cм, максимальная рабочая температура которой была $900^{\circ}$. Все опыты проводились при этой температуре. В реакторе (кварцевой трубке) слой угля имел длину $12-14$ см, объем $2-4$ мл, концы трубки были заполнены зернами кварца.

Количественному определению кислорода могут препятствовать следующие явления: 1) неполное восстановление $\mathrm{CO}_{2}$ вследствие низкой температуры реактора; 2) образование при пиролизе непредельных углеводородов и водорода, которые вместе с СО проходят детектор.

Образующийся водород трудно отделить, поэтому для устранения его влияния в качестве газа-носителя применялся гелий, теплопроводность. которого мало отличается от теплопроводности водорода.

Для отделения $\mathrm{CO}_{2}$ и непредельных углеводородов от $\mathrm{CO}$ продукты пиролиза пропускали в газе-носителе через угольную колонку, поставленную между реактором и детектором. Колонка имела длину 25 см, диаметр - 4 мм, температура - комнатная.

Хроматограммы, полученные в опытах с угольной колонкой и без нее, оказались одинаковыми. Это означает, что $\mathrm{CO}_{2}$ и летучие углеводороды при пиролизе не образовались, углеводородные остатки молекул разложились до углерода и водорода.

Для дополнительной проверки этого обстоятельства смеси углеводородов пиролизовали без угольной колонки за реактором. Как показывают хроматограммы на рис. 2 , пики продуктов пиролиза углеводородов низкие, следовательно они не могут обуславливать существенную ошибку при детектировании СО. Исходя из этого дальнейшее хроматографирование проводили без угольной колонки.

Для устранения влияния относительно низкой температуры в реакторе $\left(900^{\circ}\right)$ восстановителем в первых опытах служил плати-

Рис. 2. Пиролиз ароматических углеводородов $\mathrm{C}_{6}-\mathrm{C}_{9}$ на угле: $a-$ хроматограмма 5 мкл исходной смеси; б-хроматограмма 10 мкл смеси, полученная после пиролиза элюатов. Газ-носитель -
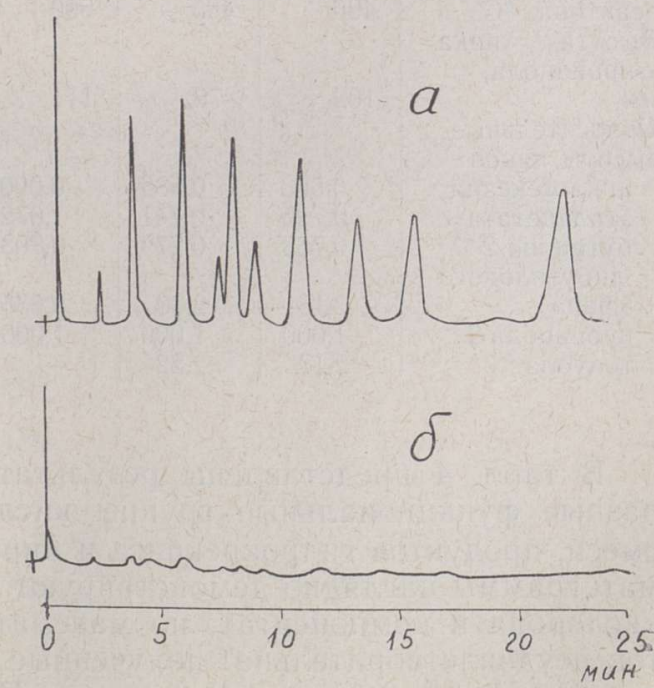
гелий. 
низированный уголь (содержание Pt 20\%). Пиролиз на нем шел хорошо, но после пропускания 200 мкл вещества катализатор отравлялся. Соединения на нем полностью не разлагались, за угловодородными пиками образовались отрицательные пики, происхождение которых установить не удалось. Также недолго работал катализатор палладий-уголь.

В дальнейшем использовали березовый уголь $(0,3 \div 1,0$ мм $)$ без прибавки. Этот наполнитель не отравлялся, продукты неполного восстановления не были заметны, несмотря на низкую температуру в реакторе.

Для вычисления содержания кислорода по продуктам пиролиза необходимо построить следующую калибровочную кривую:

$$
\frac{\text { относительная высота пика исходного вещества }}{\text { относительная высота соответствующего пика СО }}-\mathrm{C} / \mathrm{O} \text {. }
$$

Так как чувствительность катарометра зависит также от групговой принадлежности исходного вещества [11], то для каждой группы соединений необходимо строить отдельную калибровочную кривую. Если функциональные группы компонентов неизвестны или компоненты относятся к разным группам, этот способ не может быть использован. Тогда целесообразнее применить комбинированный метод анализа: получить при гидрокрекинге относительные высоты пиков углерода (метана) компонентов, полученные данные разделить на соответствующие величины содержания кислорода (CO) компонентов и последние результаты, в свою очередь, умножить на отношение С/O ключевого компонента. Так как последний вариант универсален, то расчеты, связанные с ним, проще. В настоящей работе пользовались им.

таблица 4

Определение отношения С/O разных соединений комбинированием гидрокрекинга и пиролиза

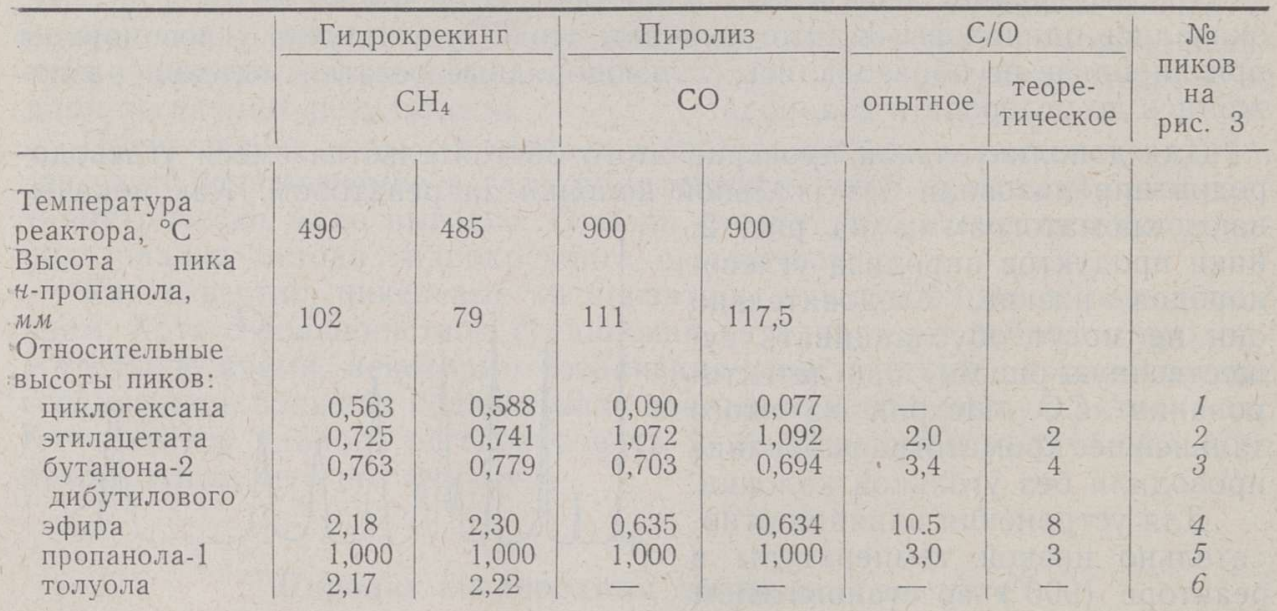

В табл. 4 представлены результаты анализа соединений, имеющих разные функциональные группы кислорода. Хроматограммы исхсдной смеси, продуктов гидрокрекинга и пиролиза изображены на рис. 3. Хроматограммы наглядно демонстрируют различное содержание углерода и кислорода в компонентах, но математическая интерпретация результатов неудовлетворительна: полученные отношения С/O для 2-бутанона и дибутилэфира далеки от истинных. По-видимому, различные функцио- 
нальные группы кислорода оказывают свое специфическое, различное влияние на результаты, искажая их.

Более удовлетворительными были результаты в случае соединений, принадлежащих к одной группе.

В табл. 5 и 6 представлены данные, полученные при анализе простых эфиров и циклокетонов. Соответствуюгцие хроматограммы приведены на рис. 4 и 5 . Хотя отклонения от теоретических еще значительные (диоксан, диамиловый эфир), резульгаты показывают, что методом можно пользоваться также при $\mathrm{C} / \mathrm{O}>5$.

Все описанные операции пиролиза были проведены в токе гелия. В работе [19] применялся водород. Мы также проверяли возможность применения водорода в качестве газаносителя. Можно было ожидать, что если восстановление пойдет по реакии (2), то большие количества водорода, возможно, подавят желательную реакцию конверсии воды, особенно при относительно низкой температуре $\left(900^{\circ}\right)$. Но эти опасения не оправдались: пиролиз в токе водорода дал результаты, близкие к полученным в токе гелия. Некоторые различия все-таки существуют, и зависят они от количества угля в реак-

торе. При 4 мл угля в токе гелия от углеводородов остались остатки (см. рис. 3 -5), которые в токе водорода почти исчезли. Это указывает на то, что они содержали водород. Уменьшение количества угля на

Таблица .5

Определение отношения С/O простых эфиров комбинированием гидрокрекинга и пиролиза

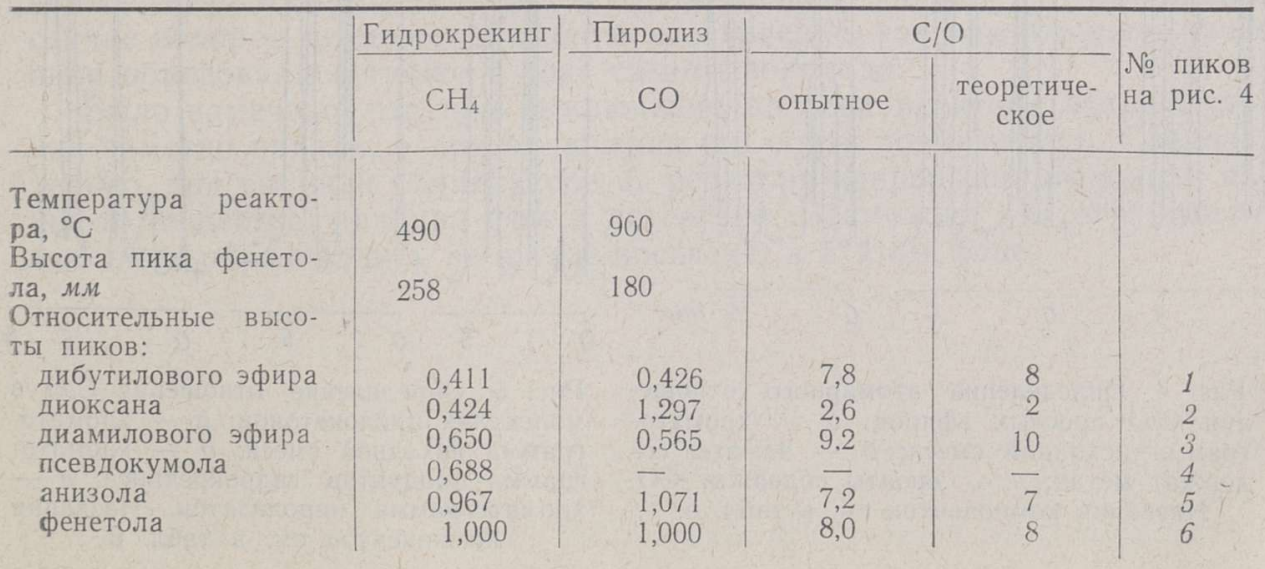


Таблица 6

Определение отношения $\mathrm{C} / \mathrm{O}$ циклокетонов комбинированием гидрокрекинга и пиролиза

\begin{tabular}{|c|c|c|c|c|c|}
\hline & Гидрокрекинг & \multirow{2}{*}{$\begin{array}{c}\text { Пиролиз } \\
\text { СO }\end{array}$} & \multicolumn{2}{|c|}{$\mathrm{C} / \mathrm{O}$} & \multirow{2}{*}{$\begin{array}{l}\text { № пиков } \\
\text { на рис. } 5\end{array}$} \\
\hline & $\mathrm{CH}_{4}$ & & опытное & $\begin{array}{c}\text { теоретиче- } \\
\text { ское }\end{array}$ & \\
\hline $\begin{array}{l}\text { Температура реакто- } \\
\text { ра, }{ }^{\circ} \mathrm{C} \\
\text { Высота пика цикло- } \\
\text { гексана, лм } \\
\text { Относительные высо- } \\
\text { ты пиков: } \\
\text { циклопентанона } \\
\text { мезитилена } \\
\text { циклогексанона } \\
\text { метилциклогексано- } \\
\text { на } \\
\text { диметилциклогекса- } \\
\text { нона }\end{array}$ & $\begin{array}{l}0,685 \\
1,207 \\
1,000 \\
0,800 \\
0,826\end{array}$ & $\begin{array}{l}\frac{0,771}{1,000} \\
0,668 \\
0,617\end{array}$ & $\begin{array}{l}\frac{5,0}{6,0} \\
7,2 \\
8,1\end{array}$ & $\begin{array}{l}5 \\
6 \\
7 \\
8\end{array}$ & $\begin{array}{l}1 \\
2 \\
3 \\
4 \\
4 \\
5\end{array}$ \\
\hline
\end{tabular}

опыты в токе гелия не влияло. При 2 мл угля в токе водорода из компонентов образовалось немного соединений, которые могли задерживаться в угольной колонке. Это свидетельствует о том, что пиролиз протекал неполно, оставались неразложившиеся углеводороды.
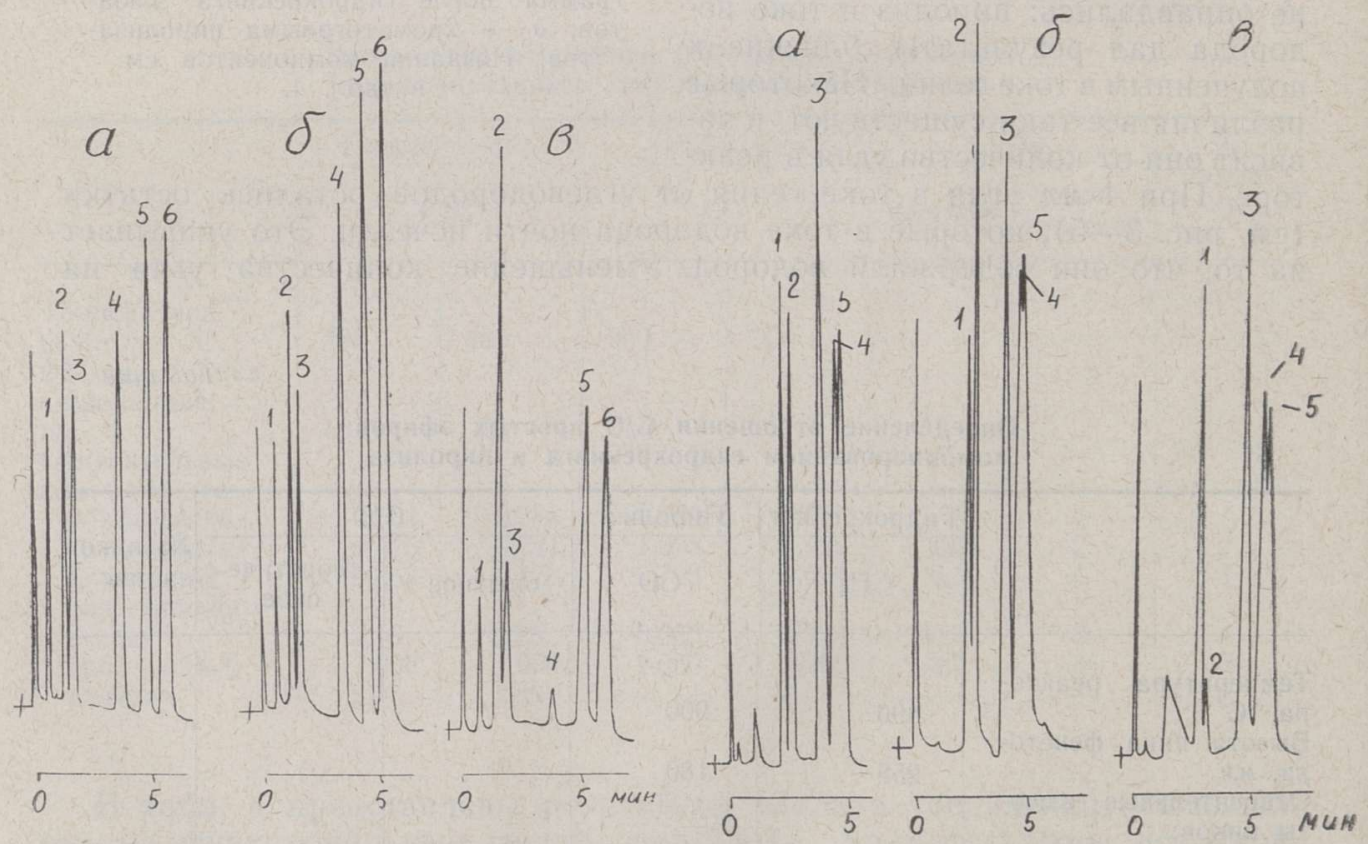

Рис. 4. Определение атомарного отношения С/O простых эфиров: $a$ - хроматограмма исходной смеси; $\sigma$ - элюаты содержат метан; в- элюаты содержат СО. Названия компонентов см. в табл. 5.

Рнс. 5. Определение отношения $\mathrm{C} / \mathrm{O}$ в молекулах циклокетонов: $a$ - хроматограмма исходной смеси; б - хроматограмма продуктов гидрокрекинга; в хроматограмма пиролизатов. Названия компонентов см. в табл. 6. 


\section{Обсуждение результатов}

Разработка методики гидрокрекинга показала, что метод можно использовать при $\mathrm{C} / \mathrm{O} \leqslant 5$. Несмотря на точные данные о содержании углерода, низкая чувствительность детектора к воде ограничивает применение метода.

Пиролиз дает точные данные о содержании кислорода, так как піовшается чувствительность детектора к нему - молекулярная теплопроводность воды и СО равны состветственно 21 и 42 [11]. Наилучшие результаты дает комбинированное использование обонх методов. Как показывают опытные данные, результаты нередко отличаются от теоретических, однако изучить все источники ошибки в ходе настоящей работы не удалось. Один из них - некоторое расширение пиков при пиролизе. Возможно, что это явление связано с уменьшением количества вещества при пиролизе.

Для прямого газохроматографического анализа обычно применяли $4-5$ мкл вещества. При гидрокрекинге объем элюатов в несколько раз увеличивается, вследствие чего для получения пиков, имеющих ту же высоту, нужно в два раза меньше материала. Продукты пиролиза состоят только из СО, поэтому для получения пиков нормальной высоты следует расходовать 8-10 мкл вещества.

Достоверные математические результаты можно получить при анализе компонентов, имеющих близкне свойства. При этом пик ключевого компонента должен лежать на хроматограмме недалеко от других пиков. Метод можно с полной уверенностью использовать в пределе $\mathrm{C} / \mathrm{O} \leqslant 10$, если сравнивать высоты близлежащих пиков исходного вещества и продуктов реакции. Если отношение высот при крекинге или пиролизе изменяется, то компоненты содержат различные количества кислорода (см. рис. 4 , пики 5 и 6 ).

В ходе этой работы остались неясными некоторые явления. Обычно в газовой хроматографии уменьшение количества анализируемого вещества повышает точность разделения. В настоящей работе все описанные опыты проведены при чувствительности детектора 5 мв (предел шкалы потенциометра). При уменьшении пробы (чувствительность 1 мв) относительные высоты пиков в параллельных опытах не были стабильными. Это явление наблюдалось как при гидрокрекинге, так и пиролизе. При малых пробах было также замечено хвостообразование у пиков. Остается неясной и причина образования отрицательных пиков при отравленном восстановителе Pt-уголь. Известно, что водород может образовать в токе гелия и отрицательные, и положительные пики $\left[{ }^{21}\right]$. В настоящем случае водород не может вызывать это явление, так как отрицательные пики образовались также в токе самого водорода.

Было замечено, что при выключении нагрева реактора нулевая линия заметно падала, а при включении его опять поднималась. Следовательно, при высокой температуре из реактора непрерывно выходили какие-то вещества, дающие фон в детекторе. Возможно, что отрицательные пики образовались не в газе-носителе, а в этом фоне. 


\title{
ЛИ Т Е Р А Т У P A
}

1. Fr a n cis H. J., Anal. Chem., 36, No. 7, 31 A (1964).

2. Cacace F., Cipolli ni R., Perez G., Anal. Chem., 35, No. 10, 1348 (1963).

3. Ревельский И. А., Бородулина Р. И., Хохлова Т. О., Нефтехимия, 4, № 4, 624 (1964).

4. Ревельский И. А., Бородулина Р. И., Климова В. Г., Соваков а Т. М., Нефтехимия, 5, № 3, 417 (1965).

5. Nightinga 1 e C. F., W a 1 ker J. M., Anal. Chem., 34, No. 11, 1435 (1962).

6. Okuno J., Morris J. C., H a ines W. E., Anal. Chem 34, No. 11, 1427 (1962).

7. Бобр ан ски й Б., Количественный анализ органических соединений, - M., 1961 , стр. 119.

8. Клесм ен т И. Р., Р анг С. А., Э йз ен О. Г., Нефтехимия 3, № 6, 867 (1963).

9. Z 1 a t k is A., R i d g w a y J. A., Nature, $182,4628,130$ (1958).

10. Z 1 a tk is A., O r o J. F., Anal. Chem. 30, 1151 (1958)

11. Messner A. E., Rosie D. M., Argabright P. A., Anal. Chem. 31,230 (1959).

12. Кестнер А. И., Ж. физ. хим., 37, № 3, 707 (1963).

13. J o h n s o n H. W., Stros s F. H., Anal. Chem., 31, 357 (1959).

14. No g a re S. D., Anal. Chem., 32, No. 5, 19 R (1960).

15. Peurifoy P. V., Ogilivie J. L., D voretzky T., J. Chromatog., 5, No. 5, 418 (1961).

16. Knight H. S., Anal. Chem., 30, 2031. (1958)

17. Колесников а Л. П., Гу ревич В. Г., С т а обинец Л. Л., Нефтехимия, 4, № 2, 340 (1964).

18. O it a J. J., C on w e y H. S., Anal. Chem., 26, 600 (1954).

19. Grötz A., B e be r H., Z. analyt. Chem., 181, No. 2, 92 (1961).

20. Eucken A., J a k o b M., Hochtemperaturoperationen, Leipzig, 1940, S. 213.

21. Purcell J. E., Ettre L. S., J. Gas Chromatog., 3, No. 2, 69 (1965).

\author{
Ннститут химии \\ Академии наук Эстонской ССР \\ Поступила в редакцию \\ $22 /$ II 1966
}

\section{KLESMENT}

\section{GAASIKROMATOGRAAFILISELT LAHUTATUD KOMPONENTIDE SUSINIKU JA HAPNIKU SUHTE OTSENE MÄÄRAMINE}

Gaasikromatograafiliste eluaatide $C$ ja $O$ suhte määramiseks töötati välja kaks reaktsioonkromatograafilist meetodit. Esimeses variandis lastakse eluaadid kandva gaasi - vesiniku - voolus $450-500^{\circ} \mathrm{C}$ temperatuuril üle nikkelkatalüsaatori, kusjuures hapnikuühendid krakitakse kvantitatiivselt metaaniks ja veeks. Diferentseeritud vee adsorbeerimisel saadakse iga ühendi $\mathrm{CH}_{4}$ ja $\mathrm{CH}_{4}+\mathrm{H}_{2} \mathrm{O}$ suhe, mis on aluseks hapnikusisalduse määramisel.

Teises variandis pürolüüsitakse hapnikuühendite eluaadid $900^{\circ}$ temperatuuril, kusjuures hapnikust saadakse $\mathrm{CO}$, süsivesinikest aga ei teki arvestusväärselt selliseid produkte, mis segaksid CO määramist.

\section{KLESMENT}

\section{DIREKTE BESTIMMUNG DES KOHLENSTOFF-SAUERSTOFF- VERHÄLTNISSES IN GASCHROMATOGRAPHISCH GETRENNTEN KOMPONENTEN}

Es wurden zwei reaktionschromatographische Methoden zur Bestimmung des $\mathrm{C} / \mathrm{O}$-Verhältnisses in gaschromatographischen Eluaten ausgearbeitet. Bei der ersten Variante wurden die Eluate auf einem Nickelkatalysator bei $450-500^{\circ}$ im Wasserstoffstrom (Trägergas) zu Methan und Wasser zersetzt. Bei der differenzialen Wasseradsorbtion wurde das $\mathrm{CH}_{4} / \mathrm{CH}_{4}+\mathrm{H}_{2} \mathrm{O}$-Verhältnis jeder Verbindung bestimmt, das der Bestimmung des Sauerstoffinhalts zugrunde liegt.

Bei der zweiten Variante werden die Sauerstoffverbindungen bei $900^{\circ}$ auf Kohle pyrolysiert, wobei CO entsteht. Aus den Kohlenwasserstoffen entstehen hier keine solche Zersetzungsprodukte, welche die Bestimmung des CO wesentlich stören könnten. 